\title{
Metformin Attenuates Myocardium Dicarbonyl Stress Induced by Chronic Hypertriglyceridemia
}

\author{
H. MALINSKA ${ }^{1}$, V. ŠKOP ${ }^{1}$, J. TRNOVSKA ${ }^{1}$, I. MARKOVA $^{1}$, P. SVOBODA $^{2}$, \\ L. KAZDOVA ${ }^{1}$, M. HALUZIK ${ }^{1}$
}

${ }^{1}$ Center for Experimental Medicine, Institute for Clinical and Experimental Medicine, Prague, Czech Republic, ${ }^{2}$ Department of Biochemistry and Microbiology, University of Chemistry and Technology, Prague, Czech Republic

Received February 2, 2017

Accepted June 19, 2017

On-line November 10, 2017

\section{Summary}

Reactive dicarbonyls stimulate production of advanced glycation endproducts, increase oxidative stress and inflammation and contribute to the development of vascular complications. We measured concentrations of dicarbonyls - methylglyoxal (MG), glyoxal (GL) and 3-deoxyglucosone (3-DG) - in the heart and kidney of a model of metabolic syndrome - hereditary hypertriglyceridemic rats ( $\mathrm{HHTg}$ ) and explored its modulation by metformin. Adult HHTg rats were fed a standard diet with or without metformin (300 mg/kg b.w.) and dicarbonyl levels and metabolic parameters were measured. HHTg rats had markedly elevated serum levels of triacylglycerols $(p<0.001)$, FFA $(p<0.01)$ and hepatic triacylglycerols $(p<0.001)$ along with increased concentrations of reactive dicarbonyls in myocardium (MG: $p<0.001 ; G L: p<0.01 ; 3-D G: p<0.01$ ) and kidney cortex (MG: $p<0.01$ ). Metformin treatment significantly reduced reactive dicarbonyls in the myocardium (MG: $p<0.05$, GL: $p<0.05$, 3-DG: $p<0.01$ ) along with increase of myocardial concentrations of reduced glutathione $(p<0.01)$ and glyoxalase 1 mRNA expression $(p<0.05)$. Metformin did not have any significant effect on dicarbonyls, glutathione or on glyoxalase 1 expression in kidney cortex. Chronically elevated hypertriglyceridemia was associated with increased levels of dicarbonyls in heart and kidney. Beneficial effects of metformin on reactive dicarbonyls and glyoxalase in the heart could contribute to its cardioprotective effects.

\section{Key words}

Hypertriglyceridemia - Dicarbonyl stress - Methylglyoxal • Glyoxalase • Metabolic syndrome $\bullet$ Metformin

\section{Corresponding author}

H. Malinska, Department of Cardio-Metabolic Research, Center for Experimental Medicine, Institute for Clinical and Experimental Medicine, Videnska 1958, 14021 Prague 4, Czech Republic. Fax: +420-261363027. E-mail: hana.malinska@ikem.cz

\section{Introduction}

The protein glycation caused by reactive dicarbonyls stimulates the production of advanced glycation end products (AGEs) and subsequently contributes to the development of chronic vascular complications, in particular in patients with diabetes (Schalkwijk et al. 2015). Under normal conditions, the excessive protein glycation is prevented through glutathione-dependent glyoxalase detoxification. An impaired balance between the generation of dicarbonyls and the efficiency of their scavenger pathways leads to dicarbonyl stress (Rabbani et al. 2015). Both of these processes are impaired in diabetic patients, where dicarbonyl generation is increased and glyoxalase activity including glutathione status is decreased (Maessen et al. 2015). Dicarbonyl stress is involved in the pathogenesis of metabolic syndrome, as well as in diabetic macro- and microvascular complications. Higher plasma levels of methylglyoxal are observed in type 1 and 2 diabetic patients (Fleming et al. 2012) and in obese patients with metabolic syndrome (Uribarri et al. 2015). In addition, it has been reported that methylglyoxal administration induces endothelial dysfunction, oxidative 
stress and impaired vasodilatation (Sena et al. 2012), and increases macrophage infiltration in adipose tissue in experimental studies (Matafome et al. 2012). An excessive generation of dicarbonyl species such as methylglyoxal (MG) is typically associated with hyperglycemia and high glucose variability (Maessen et al. 2015); nevertheless its other possible inductors include also dyslipidemia and insulin resistance (Tenenbaum et al. 2014).

Metformin, the most widely prescribed glucoselowering agent for the treatment of type 2 diabetes, has been proposed as a scavenger of reactive dicarbonyl species. It has been previously demonstrated that metformin, through the guanidine group, can bind to methylglyoxal (Kinsky et al. 2016), and that metformin treatment is able to reduce plasma methylglyoxal levels in patients with type 2 diabetes (Kender et al. 2016). We have previously demonstrated in a rat model of chronic inflammation that metformin administration decreased methylglyoxal levels in heart (Malinska et al. 2016).

In the current study we measured concentrations of dicarbonyls in the heart and the kidney of a rodent model of metabolic syndrome - non-obese hereditary hypertriglyceridemic rats. This strain originating from Wistar rats is characterized by severe hypertriglyceridemia, insulin resistance, hyperinsulinemia, hepatic steatosis and oxidative stress with an absence of obesity and hyperglycemia thus representing an experimental model of metabolic syndrome (Kazdova et al. 1997, Zicha et al. 2006). We hypothesized that severe hypertriglyceridemia and insulin resistance will be associated with increased dicarbonyl levels even in the absence of hyperglycemia and that metformin treatment will reduce dicarbonyls in both the heart and the kidney.

\section{Methods}

\section{Animals and diet}

All experiments were performed in agreement with the Animal Protection Law of the Czech Republic (311/1997) and were approved by the Ethics Committee of the Institute for Clinical and Experimental Medicine.

Six-month old Wistar male rats obtained from Charles River Laboratories (controls) and the non-obese hereditary hypertriglyceridemic strain of rats (HHTg) were used in this study. The rats were fed a standard laboratory diet with or without metformin at a dose of $300 \mathrm{mg} / \mathrm{kg}$ b.w. for 4 weeks. At the end of experiments, animals were sacrificed in a postprandial state.

\section{Analytic methods/Biochemical analyses}

Serum levels of triacylglycerols, glucose, total cholesterol, HDL-cholesterol and FFA were measured using commercially available kits (Erba Lachema, Brno, Czech Republic and Roche Diagnostics, Mannheim, Germany). Serum insulin and carboxymethyl lysine (CML) concentrations were determined using a Mercodia Rat Insulin ELISA kit (Mercodia AB, Uppsala, Sweden) and a Rat CML ELISA kit (Mybiosource, San Diego, USA). Plasma and urine lactate were analyzed electrochemically using ion-selective electrodes (Radiometer, Czech Republic). $\beta$-hydroxybutyrate and acetoacetate plasma concentrations were determined using an enzymatic method, as previously described (Galán et al. 2001).

For the oral glucose tolerance test (OGTT), blood glucose was determined after a glucose load ( $3 \mathrm{~g}$ of glucose $/ \mathrm{kg}$ b.w.) administered intragastrically after overnight fasting. The blood glucose concentration were determinated through analysis of blood samples collected from the tail at $0,30,60,120$ min after glucose loading. The area under curve (AUC) for glucose was calculated over the $120 \mathrm{~min}$ period.

For determination of tissue triacylglycerols, samples were extracted in chloroform/methanol and further processed as described previously (Malinska et al. 2015).

Levels of reduced (GSH) and oxidized (GSSG) forms of glutathione were determined using a high-performance liquid chromatography method with fluorescent detection in accordance with the HPLC diagnostic kit (Chromsystems, Gräfelfing, Germany).

\section{Dicarbonyl stress parameters}

Dicarbonyl concentrations were determined after derivatization with 1,2-diamino-benzene and using the HPLC method with fluorescence detection according to Fleming and Bierhaus (Thornalley et al. 1999).

Glo-1 activity was analyzed using the method described by Arai et al. (2014). Red blood cells were collected by centrifugation of blood (EDTA) samples and washed 3 times with $0.01 \mathrm{M}$ PBS (pH 7.4). Washed cells were lysed using cold deionized water. Hemoglobin concentrations were determined according to the Drabkin's assay (Sigma-Aldrich, Prague, Czech Republic).

\section{Glyoxalase 1 mRNA expression}

Total RNA was isolated from the kidney cortex and left ventricle using RNA Blue (Top-Bio, Praha, 
Czech Republic). Reverse transcription and quantitative real-time PCR analyses were performed using the TaqMan RNA-to $\mathrm{C}_{\mathrm{T}}$ 1-Step Kit and TaqMan Gene Expression Assay (Applied Biosystems, Foster City, USA) and carried out using a ViiA ${ }^{\mathrm{TM}} 7$ Real Time PCR System (Applied Biosystems, Foster City, USA). Relative expression of Glo-1 was determined after normalization against $\beta$-actin as an internal reference and calculated using the $2^{-\Delta \Delta C t}$ method.

\section{Cell cultures, treatment}

Confluent Human Kidney HEK293 cells were cultivated in a control medium (DMEM, Hyclone, USA) supplemented with $10 \%$ FBS, Biochem, Germany) and treated with either $0.5 \mathrm{mM}$ metformin or a combination of $0.5 \mathrm{mM}$ metformin and $10 \mathrm{mM}$ lactate (Sigma-Aldrich, Prague, Czech Republic) for $18 \mathrm{~h}$. Cells were then trypsinized and methylglyoxal content was determined in aliquots containing $15^{*} 10^{6}$ cells according to the method described above.

\section{Statistical analysis}

Statistical analysis was performed using either a one-way ANOVA Kruskal-Wallis test with multiple comparisons or a Mann-Whitney test. A value of $\mathrm{p}<0.05$ was considered to be statistically significant. The Pearson correlation was calculated to determine the relationship between glutathione and methylglyoxal in the myocardium. Data are presented as mean \pm SEM with $95 \%$ CI.

\section{Results}

The effect of hypertriglyceridemia on basal metabolic parameters

Compared with controls, hypertriglyceridemic rats exhibited markedly elevated serum levels of triacylglycerols, FFA and ectopic triacylglycerol accumulation in the liver and muscle, impaired glucose tolerance, hyperinsulinemia and increased AGE product carboxymethyl lysine (CML) and ketone bodies (Table 1).

Table 1. The effects of hypertriglyceridemia and metformin on metabolic parameters.

\begin{tabular}{|c|c|c|c|c|c|}
\hline & Wistar & HHTg & $\mathbf{p} 1<$ & $\begin{array}{c}\text { HHTg + } \\
\text { metformin }\end{array}$ & $\mathbf{p} 2<$ \\
\hline Body weight (g) & $480.00 \pm 22.00$ & $483.00 \pm 23.00$ & NS & $450.00 \pm 12.00$ & 0.05 \\
\hline Serum triglycerides $(\mathrm{mmol} / \mathrm{l})$ & $1.37 \pm 0.23$ & $4.78 \pm 0.43$ & 0.01 & $2.39 \pm 0.13$ & 0.02 \\
\hline FFA (mmol/l) & $0.19 \pm 0.03$ & $0.83 \pm 0.06$ & 0.01 & $0.70 \pm 0.08$ & 0.05 \\
\hline Cholesterol (mmol/l) & $1.72 \pm 0.10$ & $1.54 \pm 0.10$ & NS & $1.91 \pm 0.33$ & NS \\
\hline$H D L-C(\mathrm{mmol} / \mathrm{l})$ & $1.24 \pm 0.05$ & $0.75 \pm 0.03$ & 0.01 & $1.23 \pm 0.08$ & 0.02 \\
\hline Triglycerides in the liver ( $\mu \mathrm{mol} / \mathrm{g})$ & $4.32 \pm 0.70$ & $13.87 \pm 2.23$ & 0.01 & $9.20 \pm 1.22$ & 0.05 \\
\hline Triglycerides in muscle ( $\mathrm{mmol} / \mathrm{g})$ & $4.96 \pm 1.95$ & $8.43 \pm 1.64$ & 0.05 & $8.55 \pm 1.70$ & NS \\
\hline Fasting glucose $(\mathrm{mmol} / \mathrm{l})$ & $3.86 \pm 0.13$ & $5.30 \pm 0.27$ & 0.05 & $4.49 \pm 0.26$ & NS \\
\hline Insulin (pmol/l) & $469.00 \pm 30.00$ & $580.00 \pm 83.00$ & 0.05 & $225.00 \pm 28.00$ & 0.01 \\
\hline$A U C_{0-120}(\mathrm{mmol} / \mathrm{l})$ & $674.00 \pm 9.00$ & $787.00 \pm 19.00$ & 0.05 & $818.00 \pm 44.00$ & NS \\
\hline$\beta$-hydroxybutyrate $(\mu \mathrm{mol} / \mathrm{l})$ & $45.50 \pm 2.60$ & $91.60 \pm 2.90$ & 0.01 & $127.90 \pm 6.30$ & 0.01 \\
\hline Acetoacetate $(\mu \mathrm{mol} / \mathrm{l})$ & $27.10 \pm 4.90$ & $44.30 \pm 6.60$ & 0.01 & $39.10 \pm 4.90$ & NS \\
\hline$C M L(n g / m l)$ & $104.70 \pm 1.00$ & $131.00 \pm 6.50$ & 0.05 & $130.80 \pm 1.10$ & NS \\
\hline GSH/GSSG in myocardium & $4.01 \pm 0.16$ & $2.15 \pm 0.09$ & 0.05 & $4.65 \pm 0.26$ & 0.01 \\
\hline GSH/GSSG in kidney cortex & $20.22 \pm 0.87$ & $20.04 \pm 0.26$ & NS & $18.48 \pm 0.13$ & NS \\
\hline
\end{tabular}

Data are mean \pm SEM. $n=8 . \mathrm{P} 1-\mathrm{HHTg}$ vs. Wistar. P2 $-\mathrm{HHTg}+$ metformin vs. HHTg.

In hypertriglyceridemic rats we observed markedly increased serum levels of methylglyoxal $(1.802 \pm 0.121 \quad$ vs. $\quad 0.662 \pm 0.161 \mathrm{nmol} / \mathrm{ml}, \quad \mathrm{p}<0.01)$. Concentrations of individual reactive dicarbonyls in the myocardium and kidney cortex were significantly elevated in HHTg rats (Fig. 1) compared to normotrigly- ceridemic controls.

Hypertriglyceridemia was also associated with impaired glutathione metabolism in the myocardium as shown in Figure 2A. The reduced form of glutathione was decreased and the oxidized form of glutathione was increased in the myocardium of HHTg rats. 
A
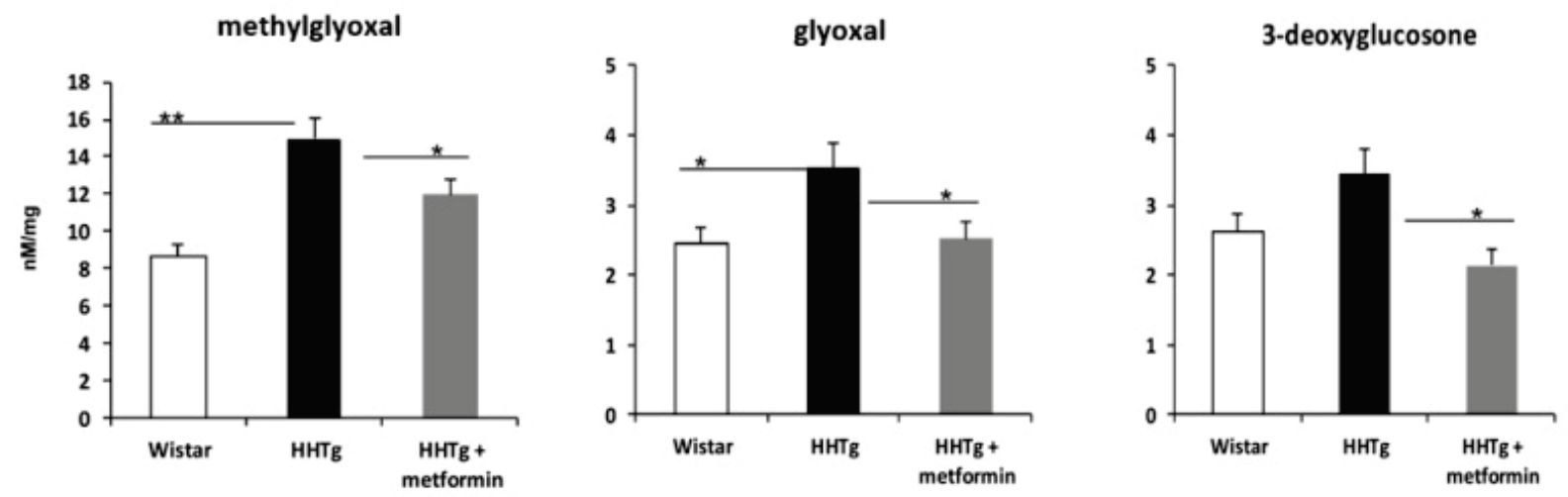

B
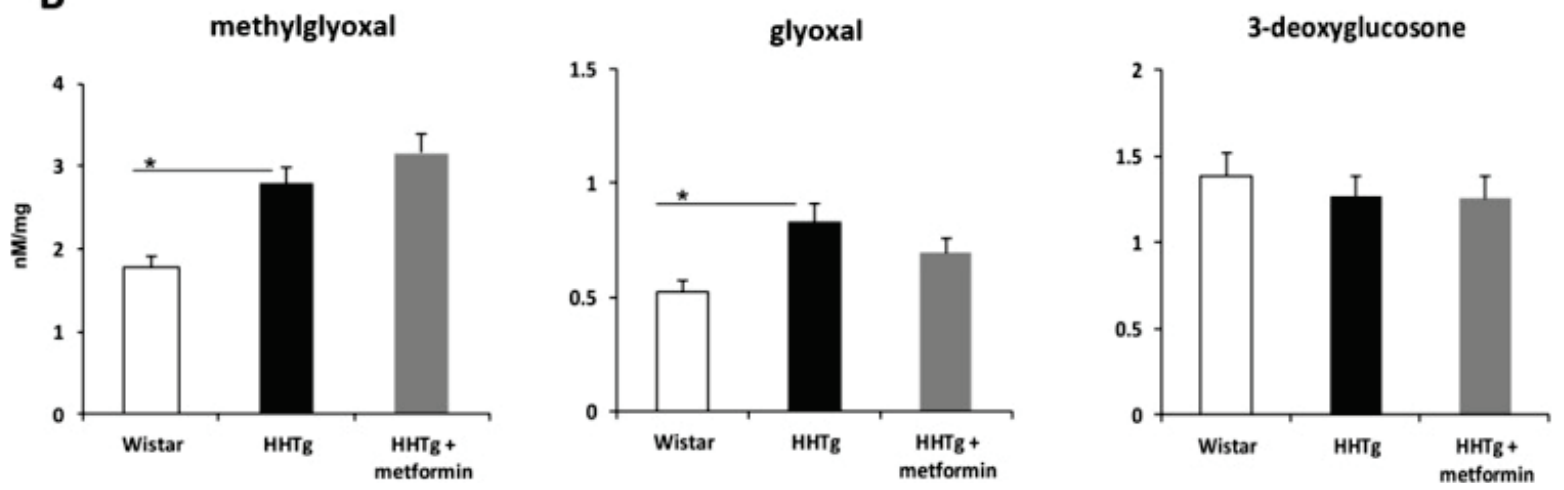

Fig. 1. The effects of hypertriglyceridemia and metformin on dicarbonyl levels in myocardium (A) and kidney cortex (B). Data are expressed as mean \pm SEM. $* p<0.05, * * p<0.01$.

A
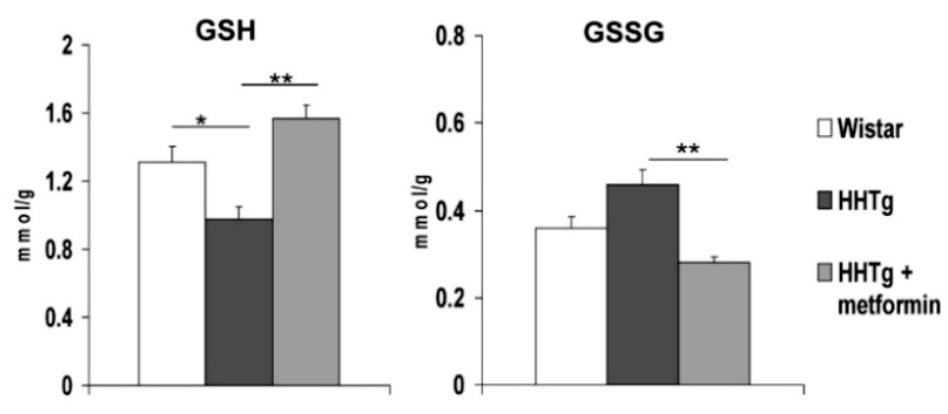

B
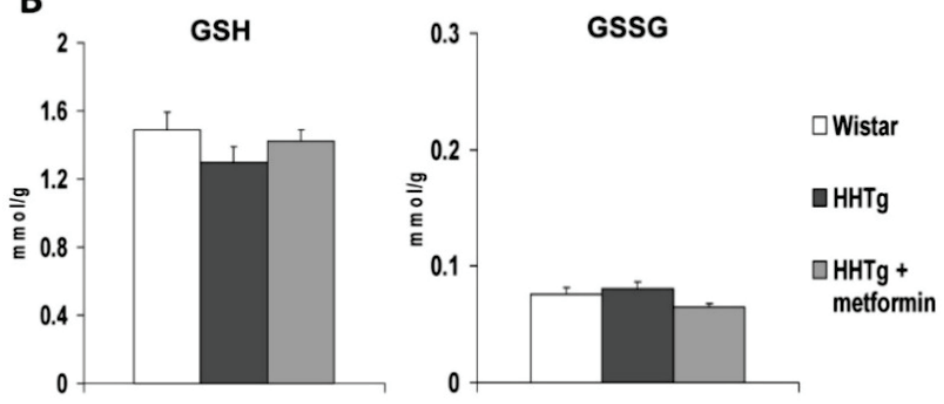

C

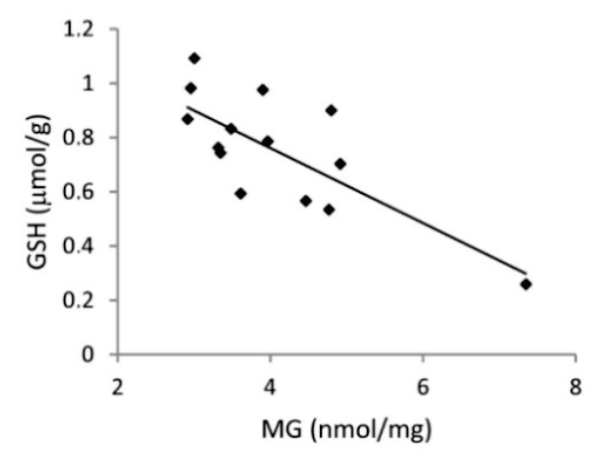

Fig. 2. The effects of hypertriglyceridemia and metformin on glutathione in myocardium (A) and kidney cortex (B) and the relationship between methylglyoxal and glutathione in myocardium $(\mathbf{C})$, Spearman's correlation coefficient $R^{2}=0.5882, p<0.05$. Data are expressed as mean \pm SEM. $* p<0.05, * * p<0.01$. 


\section{The effect of metformin}

Metformin administration to HHTg rats mildly reduced body weight and had a positive effect particularly on lipid metabolism compared to untreated HHTg rats (Table 1).

As regards carbonyl stress, metformin treatment significantly reduced serum levels of methylglyoxal $(0.915 \pm 0.219$ vs. $1.802 \pm 0.121 \mathrm{nmol} / \mathrm{ml}, \quad \mathrm{p}<0.01)$, but other dicarbonyls in the serum did not change. As shown in Figure 1, metformin treatment was associated with significantly reduced levels of all measured dicarbonyls in the myocardia of HHTg rats. However, there was no significant effect of metformin on dicarbonyl concentrations in the kidney cortex (Fig. 1).

Concentrations of hydroxybutyrate, lactate and acetoacetate in plasma and urine were significantly elevated in metformin-treated HHTg rats compared to untreated rats (Fig. 4).

Incubation with metformin significantly reduced the concentration of MG in the human kidney HEK293 cell culture. However, the presence of lactate in the medium reduced the effect of metformin on $\mathrm{MG}$ in isolated kidney cells (Fig. 4).
A

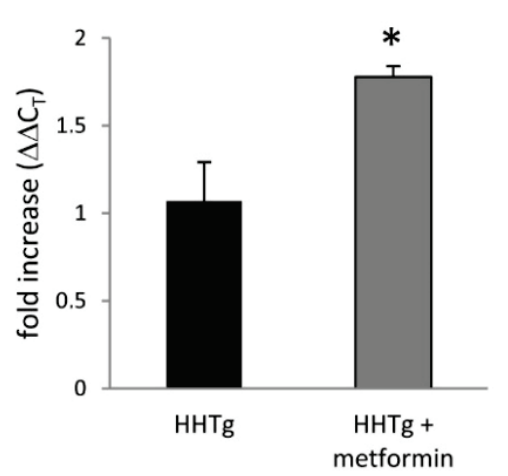

B

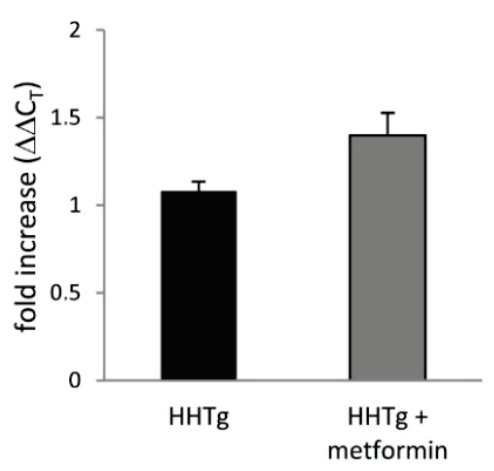

C

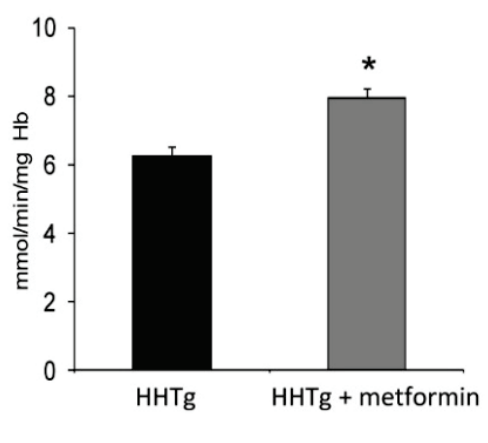

Fig. 3. The effect of metformin on glyoxalase $1 \mathrm{mRNA}$ expression in myocardium (A) and kidney cortex (B) and on glyoxalase 1 activity in erythrocytes $(\mathbf{C})$. Values are presented as mean \pm SEM. $* p<0.05$ compared to HHTg.

A

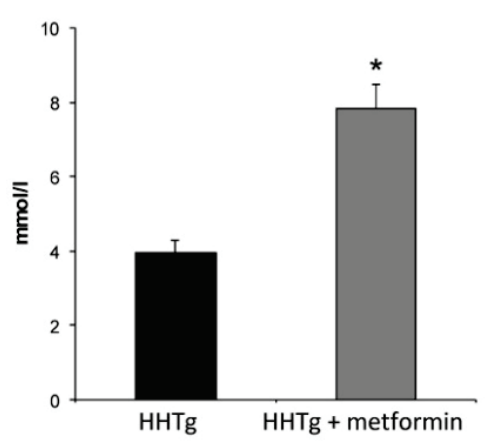

B

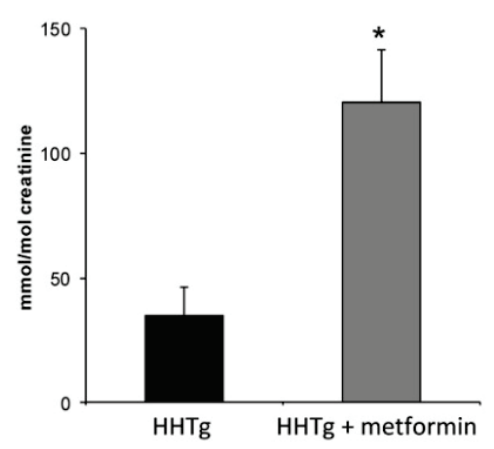

C

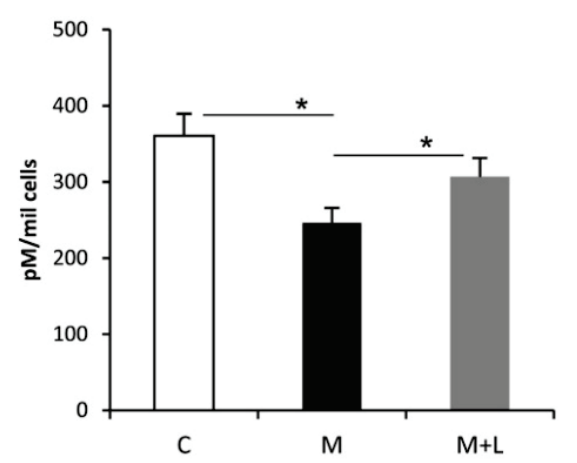

Fig. 4. The effect of metformin on lactate in plasma (A) and urine (B) and in vitro on human kidney cells (C). C - control, $\mathrm{M}-$ metformin, $\mathrm{M}+\mathrm{L}-$ metformin + lactate. Data are expressed as mean $\pm \mathrm{SEM}$. ${ }^{*} \mathrm{p}<0.05$.

\section{The effect of metformin on glutathione}

In the myocardium we observed improved glutathione metabolism in HHTg metformin-treated rats (Fig. 2), an elevation in the reduced form of glutathione and a decrease in the oxidized form of glutathione. This effect of metformin on glutathione was not observed in the kidney cortex (Fig. 2). A direct relationship between methylglyoxal and reduced glutathione in the myocardium was confirmed by negative correlation (Fig. 2C).

The effect of metformin on glyoxalase 1 expression and activity

Gene expression of mRNA Glo-1 was increased in the myocardium (left ventricle) after metformin treatment, whereas mRNA Glo-1 expression in the kidney cortex did not differ between metformin-treated 
and -untreated HHTg rats (Fig. 3). Metformin administration also significantly increased glyoxalase 1 activity measured in red blood cells compared to untreated rats.

\section{Discussion}

One of the unifying hypotheses connecting diabetes with its chronic complications suggests that enhanced metabolic flux and the deleterious effects of high glucose levels are mediated by the generation of toxic metabolites (Fleming et al. 2012). Of these, reactive dicarbonyls are among the most important (Rabbani et al. 2015). Interestingly, increased dicarbonyls production has also been described in patients with metabolic syndrome and dyslipidemia without overt diabetes suggesting their possible involvement in the increased risk in cardiovascular complications in these patients (Rabanni et al. 2016). The results of our study demonstrate for the first time that chronically elevated triglyceride and FFA levels, in the absence of obesity are associated with increased production of reactive dicarbonyl species, in particular methylglyoxal. In addition to its increased circulating levels, we observed also markedly elevated tissue levels of dicarbonyls. Previous studies have shown that MG and GL can be produced from oxidized lipids, both within their degradation and during lipoperoxidation (Turk et al. 2011) or by increased glyceroneogenesis in triacylglycerols/FFA cycle (Masania et al. 2016). Although lipid metabolism in myocardium and kidney is slightly different, the elevation of dicarbonyls in these tissues in HHTg rats is nearly the same so is implausible to significantly influence the creation of dicarbonyls. Other possible mechanisms of hypertriglyceridemiainduced dicarbonyl accumulation include increased oxidative stress, increased ketogenesis and subsequent AGE formation (Dornadula et al. 2015). Our experimental results in hypertriglyceridemic rats support the increasing evidence that chronically increased lipids can be as important as carbohydrates in the stimulation of excessive reactive dicarbonyl species production.

The massive accumulation of dicarbonyls in the myocardium of hypertriglyceridemic rats in our study was associated with an impaired balance of GSH status. It has been shown that adequate levels of the reduced form of glutathione are important for optimal activity of the glyoxalase system, which is involved in the detoxification of MG and GL (Rabanni et al. 2016). An inverse relationship between $\mathrm{MG}$ and reduced glutathione in the myocardium suggests a possible direct relationship. One the mechanisms could be a MG-induced deactivation of the antioxidant enzyme glutathione reductase thus further enhancing the potential for oxidative stress damage. Other studies have shown that high serum and adipose tissue levels of MG are closely related to insulin resistance in fructose-fed rats (Jia et al. 2007), and MG treatment in vitro impairs insulin-signaling activation in skeletal muscle cells (Riboulet-Chavey et al. 2006) through increased oxidative stress and direct effects on insulin signaling pathway (Nigro et al. 2014).

In our current study, we focused on the effects of metformin treatment on dicarbonyl levels and its metabolic consequences. Previous studies have shown that metformin may have numerous beneficial effects independent of its glucose lowering properties including cardioprotective effects (Rena et al. 2013). Our previous study in SHR rats with transgenic expression of human CRP (Malinska et al. 2016) demonstrated metformininduced decrease of methylglyoxal in the heart. Here we focused on the possible mechanisms that could explain metformin effects on dicarbonyl stress. In our current study in hypertriglyceridemic rats, metformin treatment reduced dicarbonyl accumulation and increased Glo-1 expression in the myocardium. Both of these changes could have contributed to and partly explain the cardioprotective effects of metformin seen in clinical practice. Other studies have shown that metformin improves the GSH/GSSG balance in the myocardium and prevents dicarbonyl accumulation as a cofactor of the glyoxalase system (Ashour et al. 2012, Foretz et al. 2014). Metformin has also been proposed as a scavenger of methylglyoxal (Rena et al. 2013, Kinsky et al. 2016).

Our data show that metformin can decrease MG directly through the activation of its key detoxification enzyme, Glo-1. Another important mechanism involves the interaction and activation of redox-sensitive transcription factors such as Nrf2, AP1 and NFKB, which can again upregulate Glo-1 transcription (Xue et al. 2012). At the transcriptional level, apart from Glo-1, metformin has been also shown to restore key antioxidant defense enzymes such as glutathione-S-transferase and catalase (Kender et al. 2014).

In our study, untreated HHTg rats had elevated circulating levels of ketone bodies, which were further increased by metformin treatment. Metformin is capable to readdress fatty acid metabolism from lipogenesis towards fat oxidation and ketone body production, so increased $\beta$-hydroxybutyrate after metformin 
administration can associated with increased fatty acid oxidation. Although the development of severe lactate acidosis is perceived as a negative consequence associated with metformin administration (DeFronzo et al. 2016) recent trials with novel antidiabetic drugs gliflozins have suggested that moderate ketone bodies elevation could have the potential to improve myocardium metabolism (Ferrannini et al. 2016). Recent studies have reported that the failing heart relies on ketone bodies as a significant alternative fuel, when the fatty acids utilization is diminished (Aubert et al. 2016). Accumulation of ketone bodies in the myocardium occurs as a compensatory response against oxidative stress (Nagao et al. 2016). It is thus tempting to speculate that increased ketone bodies seen in our study can also generally contribute to cardioprotective effect of metformin.

Interestingly, while we observed a significant metformin-induced attenuation of dicarbonyl stress in the heart no such effects could be seen in the kidney. In our study, an incubation of isolated human kidney cell cultures with metformin rapidly reduced MG concentrations, but this effect was abolished in the presence of lactate. Likewise, the presence of lactate reduced the effect of metformin on dicarbonyl stress in kidney cells. Taken together our data suggest that the lack of improvement of dicarbonyl stress in the kidney as compared to myocardium could be due to high levels of lactate in the kidney that abolish metformin effects.
In summary, our results indicate that chronically elevated hypertriglyceridemia and FFA are associated with increased levels of methylglyoxal in serum and with markedly elevated reactive carbonyls in the heart and kidney. The beneficial effect of metformin administration on reactive dicarbonyls and glyoxalase 1 in the heart could contribute to the cardioprotective effect of metformin independently of its antihyperglycemic effect. It remains to be shown whether similar organ-specific effects of metformin on dicarbonyl stress can also be detected in humans.

\section{Conflict of Interest}

There is no conflict of interest.

\section{Acknowledgements}

This work was supported by the Ministry of Health of the Czech Republic - conceptual development of research organizations ("Institute for Clinical and Experimental Medicine - IKEM, IN 00023001”).

\footnotetext{
Abbreviations

AGE - advanced glycation end product, CML carboxymethyl lysine, FFA - free fatty acids, GSH reduced form of glutathione, GSSG - oxidized form of glutathione, TBARS - thiobarbituric acid reactive substance, TAG - triacylglycerol, MG - methylglyoxal, GL - glyoxal, 3-DG - 3-deoxyglucosone, Glo-1 glyoxalase 1 .
}

\section{References}

ARAI M, NIHONMATSU-KIKUCHI N, ITOKAWA M, RABBANI N, THORNALLEY PJ: Measurement of glyoxalase activities. Biochem Soc Trans 42: 491-494, 2014.

ASHOUR AE, SAYED-AHMED MM, ABD-ALLAH AR, KORASHY HM, MAAYAH ZH, ALKHALIDI H, MUBARAK M, ALHAIDER A: Metformin rescues the myocardium from doxorubicin-induced energy starvation and mitochondrial damage in rats. Oxid Med Cell Longev 2012: 434195, 2012.

AUBERT G, MARTIN OJ, HORTON JL, LAI L, VEGA RB, LEONE TC, KOVES T, GARDELL S, KRÜGER M, HOPPEL CL, LEWANDOWSKI ED, CRAWFORD PA, MUOIO DM, KELLY DP: The failing heart relies on ketone bodies as a fuel. Circulation 133: 698-705, 2016.

DEFRONZO R, FLEMING GA, CHEN K, BICSAK TA: Metformin-associated lactic acidosis: current perspectives on causes and risk. Metabolism 65: 20-29, 2016.

DORNADULA S, ELANGO B, BALASHANMUGAM P, PALANISAMY R, KUNKA MOHANRAM R: Pathophysiological insights of methylglyoxal induced type-2 diabetes. Chem Res Toxicol 28: 1666-1674, 2015.

FERRANNINI E, MARK M, MAYOUX E: CV protection in the EMPA-REG OUTCOME trial: A "Thrifty substrate" hypothesis. Diabetes Care 39: 1108-1114, 2016.

FLEMING T, CUNY J, NAWROTH G, DJURIC Z, HUMPERT PM, ZEIER M, BIERHAUS A, NAWROTH PP: Is diabetes an acquired disorder of reactive glucose metabolites and their intermediates? Diabetologia $\mathbf{5 5}$ : 1151-1155, 2012. 
FORETZ M, GUIGAS B, BERTRAND L, POLLAK M, VIOLLET B: Metformin: from mechanisms of action to therapies. Cell Metab 20: 953-966, 2014.

GALÁN A, HERNANDÉZ J, JIMENEZ O: Measurement of blood acetoacetate and beta-hydroxybutyrate in an automatic analyser. J Autom Methods Manag Chem 23: 69-76, 2001.

JIA X, WU L: Accumulation of endogenous methylglyoxal impaired insulin signaling in adipose tissue of fructose-fed rats. Mol Cell Biochem 306: 133-139, 2007.

KAZDOVA L, ŽAK A, VRANA A: Increased lipoprotein oxidability and aortic lipid peroxidation in an experimental model of insulin resistance syndrome. Ann N Y Acad Sci 20: 521-525, 1997.

KENDER Z, FLEMING T, KOPF S, TORZSA P, GROLMUSZ V, HERZIG S, SCHLEICHER E, RÁCZ K, REISMANN P, NAWROTH PP: Effect of metformin on methylglyoxal metabolism in patients with type 2 diabetes. Diabetes Metab Res Rev 16: 125-132, 2014.

KINSKY OR, HARGRAVES TL, ANUMOL T, JACOBSEN NE, DAI J, SNYDER SA, MONKS TJ, LAU SS: Metformin scavenges methylglyoxal to form a novel imidazolinone metabolite in humans. Chem Res Toxicol 29: 227-234, 2016.

MAESSEN DE, STEHOUWER CD, SCHALKWIJK CG: The role of methylglyoxal and the glyoxalase system in diabetes and other age-related diseases. Clin Sci 128: 839-861, 2015.

MALÍNSKÁ H, HÜTTL M, OLIYARNYK O, BRATOVA M, KAZDOVA L: Conjugated linoleic acid reduces visceral and ectopic lipid accumulation and insulin resistance in chronic severe hypertriacylglycerolemia. Nutrition 31: 1045-1051, 2015.

MALINSKA H, OLIYARNYK O, ŠKOP V, ŠILHAVY J, LANDA V, ZIDEK V, MLEJNEK P, ŠIMÁKOVA M, STRNAD H, KAZDOVA L, PRAVENEC M: Effects of metformin on tissue oxidative and dicarbonyl stress in transgenic spontaneously hypertensive rats expressing human C-reactive protein. PLoS One 11: e0150924, 2016.

MASANIA J, MALCZEWSKA-MALEC M, RAZNY U, GORALSKA J, ZDZIENICKA A, KIEC-WILK B, GRUCA A, STANCEL-MOZWILLO J, DEMBINSKA-KIEC A, RABBANI N, THORNALLEY PJ: Dicarbonyl stress in clinical obesity. Glycoconj J 33: 581-589, 2016.

MATAFOME P, SANTOS-SILVA D, CRISOSTOMO J, RODRIGUES T, RODRIGUES L, SENA CM, PEREIRA P, SEICA R: Methylglyoxal cause structural and functional alterations in adipose tissue independently of obesity. Arch Physiol Biochem 118: 58-68, 2012.

NAGAO M, TOH R, IRINO Y, MORI T, NAKAJIMA H, HARA T, HONJO T, SATOMI-KOBAYASHI S, SHINKE T, TANAKA H, ISHIDA T, HIRATA K: $\beta$-Hydroxybutyrate elevation as a compensatory response against oxidative stress in cardiomyocytes. Biochem Biophys Res Commun 475: 322-328, 2016.

NIGRO C, RACITI GA, LEONE A, FLEMING TH, LONGO M, PREVENZANO I, FIORY F, MIRRA P, D'ESPOSITO V, ULIANICH L, NAWROTH PP, FORMISANO P, BEGUINOT F, MIELE C: Methylglyoxal impairs endothelial insulin sensitivity both in vitro and in vivo. Diabetologia 57: 1485-1494, 2014.

RABBANI N, THORNALLEY PJ: Dicarbonyl stress in cell and tissue dysfunction contributing to ageing and disease. Biochem Biophys Res Commun 458: 221-226, 2015.

RABBANI N, XUE M, THORNALLEY PJ: Dicarbonyls and glyoxalase in disease mechanisms and clinical therapeutics. Glycoconj J 33: 513-525, 2016.

RENA G, PEARSON ER, SAKAMOTO K: Molecular mechanism of action of metformin: old or new insight? Diabetologia 56: 1898-1906, 2013.

RIBOULET-CHAVEY A, PIERRON A, DURAND I, MURDACA J, GIUDICELli J, VAN OBBERGHEN E: Methlyglyoxal impairs the insulin signaling pathways independently of the formation of intracellular reactive oxygen species. Diabetes 55: 1289-1299, 2006.

SCHALKWIJK CG: Vacular AGE-ing by methylglyoxal: the past, the present and the future. Diabetologia 58: 1715-1719, 2015.

SENA CM, MATAFOME P, CRISOSTOMO J, RODRIGUES L, FERNANDES R, PEREIRA P, SEICA RM: Methylglyoxal promotes oxidative stress and endothelial dysfunction. Pharmacol Res 65: 497-506, 2012.

TENENBAUM A, KLEMPFNER R, FISMAN EZ: Hypertriglyceridemia: a too long unfairly neglected major cardiovascular risk factor. Cardiovasc Diabetol 13: 159, 2014. 
THORNALLEY PJ, LANGBORG A, MINHAS HS: Formation of glyoxal, methylglyoxal and 3-deoxyglucosone in the glycation of proteins by glucose. Biochem J 344: 109-116, 1999.

TURK Z, ČAVLOVIČ-NAGLIČ M, TURK N: Relationship of methylglyoxal-adduct biogenesis to LDL and triglycerides levels in diabetics. Life Sci 89: 485-490, 2011.

URIBARRI J, CAI W, WOODWARD M, TRIPP E, GOLDBERG L, PYZIK R, YEE K, TANSMAN L, CHEN X, MANI V, FAYAD ZA, VLASSARA H: Elevated serum advanced glycation endproducts in obese indicate risk for the metabolic syndrome: a link between heathy and unhealthy obesity? J Clin Endocrinol Metab 100: 1957-1966, 2015.

XUE M, RABBANI N, MOMIJI H, IMBASI P, ANWAR MM, KITTERINGHAM N, PARK BK, SOUMA T, MORIGUCHI T, YAMAMOTO M, THORNALLEY PJ: Transcriptional control of glyoxalase 1 by Nrf2 provides a stress-responsive defence against dicarbonyl glycation. Biochem J 443: 213-222, 2012.

ZICHA J, PECHÁNOVÁ O, CACÁNYIOVÁ S, CEBOVÁ M, KRISTEK F, TÖRÖK J, SIMKO F, DOBESOVÁ Z, KUNES J: Hereditary hypertriglyceridemic rats: a suitable model of cardiovascular disease and metabolic syndrome? Physiol Res 55 (Suppl 1): S49-S63, 2006. 